\title{
DISCUSSÃO SOBRE TÉCNICAS E MATERIAIS UTILIZADOS NA EDUCAÇÃO AMBIENTAL E SUA APLICABILIDADE NO TRABALHO JUNTO AOS SURDOS
}

Carlos Alexandre Rodrigues Pereira ${ }^{1}$

Juliana Valéria de Melo²

Resumo: A Educação Ambiental para surdos durante a educação básica no Brasil ainda é tema pouco discutido. Realizou-se em 2011 um estudo de caso de uma Escola para surdos em um município do Triângulo Mineiro sobre a Educação Ambiental para os alunos surdos dessa Instituição. Durante a pesquisa verificou-se a carência de materiais para o trabalho educativo ambiental e não foram localizados textos que discutissem métodos e práticas de Educação Ambiental que fossem aplicáveis ao contexto dos alunos surdos. Para promover a discussão de técnicas e materiais utilizados na Educação Ambiental e sua aplicabilidade no trabalho junto aos surdos, elaborou-se este artigo que se baseia nas verificações da pesquisa anteriormente realizada.

Palavras-chave: Surdez; Educação Especial; Meio Ambiente.

\footnotetext{
${ }^{1}$ Escola Nacional de Saúde Pública Sérgio Arouca - Ensp. E-mail: carlos.rpereira@hotmail.com

2Universidade Estadual de Campinas - Unicamp. E-mail: julianamelo_to@hotmail.com.
} 


\section{Introdução}

A Educação Ambiental em ambiente escolar é requisito obrigatório no Brasil, regulamentada pela Política Nacional de Educação Ambiental (BRASIL, 1999). Porém este é um tema ainda pouco discutido no que se refere à educação dos surdos. Uma vez obrigatória, seja nas escolas especiais ou regulares, fica a dúvida de como a Educação Ambiental para surdos deve ser desenvolvida em ambiente escolar, uma vez que a educação dos surdos ocorre por meio de uma sistemática diferente da usual voltada às pessoas ouvintes. $O$ trabalho em meio ambiente deve considerar seus aspectos linguísticos e culturais próprios, vez que, segundo Goldfeld (2002), a educação da pessoa surda se dá em uma atmosfera espaço-visual diferente do usual.

Pouco se sabe sobre: quais assuntos são abordados, como a eficácia das ações é avaliada e quais são os resultados alcançados pela Educação Ambiental voltada para surdos, apesar de haver alguns relatos de ações de Educação Ambiental junto à pessoa Surda como Demamann (2006), Trajano et al (2008), Albuquerque (2009) e Diário da Manhã (2011), por exemplo.

Dessa forma, é importante discutir quais técnicas e abordagens são utilizadas para a Educação Ambiental nas escolas e qual a sua aplicabilidade junto aos Surdos. É necessário, também, difundir a Educação Ambiental como um processo, diferenciando-a da simples conscientização, reconhecendo-a como um processo sociopolítico capaz de trazer melhorias concretas no meio ambiente e na qualidade de vida das pessoas envolvidas (MAZZINI, 2004).

Realizou-se em 2011 um estudo de caso de uma Escola para surdos em um município de Minas Gerais, no Triângulo Mineiro sobre a Educação Ambiental para os alunos surdos dessa Instituição. Durante a pesquisa verificouse a carência de materiais para o trabalho educativo ambiental e não foram localizados textos que discutissem métodos e práticas de Educação Ambiental que fossem aplicáveis ao contexto dos alunos surdos. Para promover a discussão de técnicas e materiais utilizados na Educação Ambiental e sua

aplicabilidade no trabalho junto aos surdos, elaborou-se este artigo que se baseia nas verificações dessa pesquisa, anteriormente realizada.

\section{Os métodos e estratégias da Educação Ambiental nas escolas}

$\mathrm{Na}$ prática da Educação Ambiental com ouvintes, entende-se que é importante verificar o contexto da faixa etária e desenvolvimento da criança, para que as estratégias de trabalho escolhidas sejam adequadas para se transmitir o que se propõe. Segundo Pereira et al. (2011), a Educação Ambiental deve ser desenvolvida em linguagem adequada, que considere a percepção dos participantes sobre sua própria realidade, suas expectativas e seu entendimento do meio.

Existem várias teorias sobre o desenvolvimento infantil e segundo a interpretação de Melo (2010), a adaptação da linguagem e da atividade deve 
levar em consideração também as condições socioeconômicas, a cultura e as experiências dos participantes. No que se refere a crianças, o envolvimento delas depende da adequação das atividades ao seu estágio de desenvolvimento. Com relação a isso, no Quadro 1 estão listadas algumas sugestões de estratégias de trabalho que podem ser usadas durante a educação básica de ouvintes conforme as fases do desenvolvimento na visão dos autores.

Quadro 1: Temas e estratégias que podem ser utilizados na Educação Ambiental de alunos ouvintes da educação básica

\begin{tabular}{|c|c|c|}
\hline Idade & Temas abordados & $\begin{array}{l}\text { Estratégias e materiais utilizados na } \\
\text { Educação Ambiental }\end{array}$ \\
\hline Até 3 anos & $\begin{array}{l}\text { Temas gerais como cores, sons, } \\
\text { plantas, animais, nomes, família, casa } \\
\text { e alimentos, principalmente. }\end{array}$ & $\begin{array}{l}\text { - estimulação visual com uso de figuras e } \\
\text { cores; } \\
\text { - estimulação tátil com uso de texturas } \\
\text { (massinhas, bolas, brinquedos de diversos } \\
\text { materiais); } \\
\text { - estimulação auditiva e da fala com uso de } \\
\text { músicas e sons; }\end{array}$ \\
\hline 3 e 4 anos & 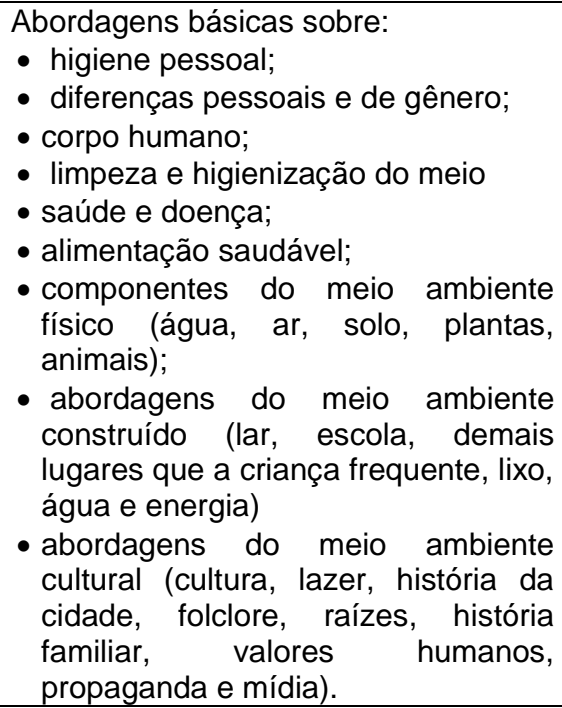 & $\begin{array}{l}\text { - músicas e cantigas; } \\
\text { - uso de fantoches; } \\
\text { - leitura (pelo professor) de livros; } \\
\text { - desenhar e colorir; } \\
\text { - dança; } \\
\text { - ilustrações; } \\
\text { - colagem e pintura; } \\
\text { - jogos em grupo. }\end{array}$ \\
\hline 5 e 6 anos & $\begin{array}{l}\text { Abordagens aprofundadas dos temas } \\
\text { anteriores e abordagens básicas de } \\
\text { temas como: } \\
\text { - problemas urbanos; } \\
\text { - desigualdades sociais; } \\
\text { - preconceito; } \\
\text { - cultura do estado, do país e dos } \\
\text { - povos; } \\
\text { - diferenças linguísticas; } \\
\text { - cidadania pessoal e vida diária; } \\
\text { - ecossistemas; } \\
\text { - problemas ambientais e alternativas } \\
\text { de soluções. }\end{array}$ & $\begin{array}{l}\text { - músicas e cantigas; } \\
\text { - desenhar e colorir; } \\
\text { - colagem e pintura; } \\
\text { - dança; } \\
\text { - dinâmicas; } \\
\text { - jogos em grupo; } \\
\text { - leitura de livros (pelo aluno); } \\
\text { - oficinas de criação de materiais, brinquedos } \\
\text { e objetos; } \\
\text { - teatro. }\end{array}$ \\
\hline
\end{tabular}

Continua...

Revbea, V. 10, № 3: 85-96, 2015. 


\begin{tabular}{|c|c|c|}
\hline Idade & Temas abordados & $\begin{array}{c}\begin{array}{c}\text { Estratégias e materiais utilizados na Educação } \\
\text { Ambiental }\end{array} \\
\end{array}$ \\
\hline 7 e 8 anos & $\begin{array}{l}\text { Abordagens aprofundadas dos temas } \\
\text { anteriores e abordagens básicas de } \\
\text { temas como: } \\
\text { - papéis e responsabilidades sociais; } \\
\text { - relacionamentos interpessoais; } \\
\text { - responsabilidade ambiental } \\
\text { (individuais, dos grupos sociais, das } \\
\text { empresas e do governo) } \\
\text { - grupos sociais e miscigenação de } \\
\text { culturas; } \\
\text { - moldagem ambiental e construção } \\
\text { - da paisagem; } \\
\text { - política e economia ambiental; } \\
\text { - profissões e mercado de trabalho; } \\
\text { - marketing e propaganda; } \\
\text { - produtos químicos, tóxicos e } \\
\text { entorpecentes; } \\
\text { - sexualidade; } \\
\text { - dinheiro, trabalho e renda. }\end{array}$ & $\begin{array}{l}\text { - aulas expositivas e discussões em grupo; } \\
\text { - desenhar, colorir, pintar; } \\
\text { - escrita de textos e formulação de pequenas histórias; } \\
\text { - oficinas de criação de materiais, brinquedos e objetos; } \\
\text { - jogos tradicionais; } \\
\text { - brincadeiras, jogos individuais e em grupo e dinâmicas; } \\
\text { - musica, dança e teatro; } \\
\text { - construção de fantoches; } \\
\text { - reaproveitamento de materiais; } \\
\text { - integração das disciplinas na discussão de temas } \\
\text { - transversais; } \\
\text { - observação de experimentos simples sobre as ciências; } \\
\text { - fotografia; } \\
\text { - vivências; } \\
\text { - atividades de raciocínio lógico; } \\
\text { - filmes. }\end{array}$ \\
\hline 9 a 12 anos & $\begin{array}{l}\text { Abordagens complexas dos temas } \\
\text { citados anteriormente e: } \\
\text { - discussão das interações ambiente- } \\
\text { ser-qualidade de vida; } \\
\text { - visão holística, transversalidade e } \\
\text { interdisciplinaridade; } \\
\text { - relação meio ambiente e saúde, } \\
\text { economia, política, trabalho e } \\
\text { cultura; } \\
\text { - modificações ambientais e seus } \\
\text { efeitos; } \\
\text { - desenvolvimento e sustentabilidade; } \\
\text { - autonomia e responsabilidade social }\end{array}$ & $\begin{array}{l}\text { - dinâmicas; } \\
\text { - observação de experimentos simples sobre as ciências; } \\
\text { - visitas orientadas, aulas de campo; } \\
\text { - integração das disciplinas na discussão de temas } \\
\text { transversais; } \\
\text { - escrita de textos; } \\
\text { - fotografia; } \\
\text { - rodas de discussão; } \\
\text { - aulas práticas e expositivas; } \\
\text { - filmes; } \\
\text { - vivências; } \\
\text { - oficinas de criação de materiais, brinquedos e objetos; } \\
\text { - teatro, música, dança; } \\
\text { - pintura, escultura e maquetaria; } \\
\text { - atividades desenvolvidas na sociedade; } \\
\text { - feiras de conhecimento; } \\
\text { - apresentação de trabalhos. }\end{array}$ \\
\hline 13 a 17 anos & $\begin{array}{l}\text { Abordagens complexas dos temas } \\
\text { anteriores e abordagens sobre: } \\
\text { - terceiro setor; } \\
\text { - percepção e linguagem ambiental; } \\
\text { - formação profissional; } \\
\text { - meio ambiente do trabalho; } \\
\text { - estruturas e organização sociais; } \\
\text { - movimentos populares; } \\
\text { - estruturas governamentais; } \\
\text { - problemas contemporâneos; } \\
\text { - saúde ambiental; } \\
\text { - construções doentes; } \\
\text { - mobilidade social; } \\
\text { - planejamento urbano; } \\
\text { - planejamento rural; } \\
\text { - efeitos tóxicos; } \\
\text { - vigilância sanitária. }\end{array}$ & $\begin{array}{l}\text { - aulas práticas e expositivas; } \\
\text { - rodas de discussão; } \\
\text { - oficinas de criação de materiais, brinquedos e objetos; } \\
\text { - filmes; } \\
\text { - fotografia; } \\
\text { - dissertações } \\
\text { - vivências } \\
\text { - teatro, música, dança; } \\
\text { - pintura, escultura e maquetaria; } \\
\text { - atividades desenvolvidas na sociedade; } \\
\text { - feiras de conhecimento; } \\
\text { - apresentação de trabalhos; } \\
\text { - iniciação à pesquisa orientada e experimentação. }\end{array}$ \\
\hline
\end{tabular}


Este quadro foi elaborado com base na experiência obtida no decorrer dos trabalhos de Educação Ambiental com pessoas ouvintes (PEREIRA; SILVA; FERNANDES, 2011). Trata-se de um agrupamento genérico e exemplificativo de atividades, realizado com base nas capacidades da criança em cada fase de desenvolvimento. Somente uma avaliação, conforme público e tema, pode identificar qual a melhor estratégia de trabalho. Variações nos assuntos podem ocorrer conforme contexto e necessidade.

Os trabalhos de Educação Ambiental junto à pessoa surda devem abordar os mesmos assuntos, mas são realizados, muitas vezes, adaptando ao contexto da cultura surda os materiais que se tem disponível para ouvintes. Adequar as estratégias de trabalho para o contexto do público surdo ainda é um desafio, uma vez que o aprendizado da pessoa surda se dá por vias diferentes do que normalmente ocorre com pessoas ouvintes. O aprendizado do surdo se dá por meio de uma atmosfera espaço-visual (GOLDFELD, 2002), por isso a utilização de imagens, a construção de espaços temáticos, a utilização dos sentidos, as oficinas temáticas e a representação tendem a facilitar 0 entendimento da abstração e subjetividade que permeiam alguns temas ambientais como cultura e valores sociais.

Utilizando-se dessas estratégias é possível trabalhar com os surdos todas as áreas citadas por Melo (2010) necessárias e aplicáveis ao trabalho educativo ambiental, apoiando o próprio desenvolvimento do indivíduo: área afetiva, vivência em grupo, comunicação, movimento, necessidades, criatividade, área cognitiva, área sensorial, área espacial, área temporal, área de análise e síntese, área psicomotora, esquema corporal, motricidade ampla e motricidade fina.

Uma prática eficaz é a de Vivências, como os passeios realizados com os alunos para que utilizem de seus sentidos, seus corpos e sua percepção para elaborar um senso que culminará na formação do conhecimento sobre o tema abordado. Essa prática não utiliza da forma tradicional de transmissão de mensagens e conhecimentos baseada na fala (MENDONÇA, 2007). Para os surdos, isso pode ter efeito positivo, no sentido de facilitar o entendimento e causar motivação. Outra técnica viável é a discussão em grupo. Deixar que o participante expresse seu ponto de vista é de fundamental importância para o autoconhecimento e construção de valores e objetivos comuns de todo o grupo.

Ao se definir as estratégias de trabalho devem-se levar em consideração quais são as habilidades pré-existentes no grupo. Segundo Junqueira (2007), o resultado do trabalho depende do esforço e habilidade pessoais, uma vez que os recursos materiais oferecidos pelo ambiente servem apenas de instrumentos para se alcançar os objetivos estabelecidos. É importante, ainda, identificar quais habilidades o grupo deseja desenvolver, uma vez que a formação de habilidades é um dos pré-requisitos para que o trabalho seja reconhecido como Educação Ambiental (BRASIL, 1999) e é de fundamental importância para que surjam ações de melhoria social como resultados do trabalho educativo. 
É necessário, ainda, que se pesquise a eficácia dessas estratégias em cada fase de desenvolvimento do surdo, para que se possa contar com parâmetros sobre quais são mais recomendáveis e em qual momento. Sem essa pesquisa, o que se pode sugerir é a utilização de estratégias que sejam relacionadas aos artefatos da cultura surda, uma vez que eles mesmos são instrumentos de construção e modificação ambiental.

Segundo STROBEL (2008), os artefatos culturais dos surdos são entendidos como as normas e valores desse grupo, ou seja, as peculiaridades da cultura surda. Segundo a autora, são eles:

- A experiência visual: artefato pelo qual os surdos percebem o mundo de maneira diferente, proporcionando reflexões sobre suas subjetividades. Devido à ausência da audição e do som, é por meio dos olhos que se percebe tudo que ocorre ao seu redor.

- Artefato linguístico: considera a língua de sinais um aspecto fundamental de cultura surda. Porém, neste artefato se incluem os gestos emergentes ou caseiros, criados no decorrer do cotidiano para facilitar a comunicação, principalmente quando não se conhece bem a língua de sinais. Para o sujeito surdo ter acesso às informações e conhecimentos e para construir sua identidade como surdo é fundamental criar uma ligação com o grupo de surdos para que possa explorar de uma língua em comum (de sinais).

- Artefato familiar: o nascimento de um surdo em uma família surda é benquisto, pois a cultura surda não entende o surdo como um problema social, como ocorre com algumas famílias ouvintes. Certos inconvenientes podem ocorrer quando um surdo está inserido em uma família ouvinte, devido à diferença de culturas. Contudo, a participação familiar no aprendizado do surdo é de fundamental importância para a construção do conhecimento, a inclusão social e a vivência em família.

- Literatura surda: é apresentada como outro artefato, pois traduz a memória das vivências surdas através das várias gerações. A literatura se compõe de gêneros como a poesia, história de surdos, piadas, literatura infantil, clássicos, fábulas, contos, romances e outras manifestações. Considera-se literatura surda aquela que tem a língua de sinais e a questão da identidade e da cultura surda presentes na narrativa.

- Vida social e esportiva: também é considerado um artefato. São acontecimentos como casamentos, festas, atividades associativistas, além de eventos esportivos e práticas de lazer. Também ocorre a habitual frequência aos bailes das associações de surdos com seus desfiles de misses surdas, discursos, entrega de troféus e outros.

- Artes visuais: os surdos fazem muitas criações artísticas que sintetizam suas emoções, suas histórias, suas subjetividades e sua cultura. Muitos surdos artistas fazem desenhos, pinturas, esculturas e outras manifestações artísticas com a expressão de beleza, equilíbrio, harmonia, ou mesmo revolta com muitas discriminações sofridas por eles.

- Política: consiste em diversos movimentos e lutas dos surdos pelos seus direitos. No Brasil, foram transmitidas muitas tradições por meio de 
organizações das comunidades surdas, sendo as associações os espaços mais conhecidos.

- Materiais: também são citados como artefatos. São resultados da transformação da natureza pelo trabalho humano; sua utilização é condicionada pelo enleio do comportamento cultural, que auxilia nas acessibilidades nas vidas cotidianas de cada um (um exemplo citado por Strobel é o TDD - Telecommunciations Device for the Deaf, também chamado de TS - Telefone para surdos, mas existem muitos outros até mais atuais como o próprio telefone celular para envio de mensagens de texto ou mesmo dispositivos luminosos em campainhas).

Cabe ressaltar que essa listagem não é exaustiva e nem se expressa da mesma forma e conteúdo entre todos os surdos, pois as pessoas possuem singularidades, desempenham diferentes papeis e vivenciam diferentes experiências que podem levar a diferentes formas de expressão desses artefatos. Contudo, como referência, pode-se dizer que atividades como fotografia, artes visuais, desenho, pintura, expressão corporal e dança são ferramentas atrativas de trabalho, uma vez que pertencem ao contexto da cultura surda.

\section{Alternativas para a potencialização do trabalho de Educação Ambiental para surdos no contexto escolar}

$\mathrm{Na}$ pesquisa realizada na escola para surdos (PEREIRA, 2013) foram identificados diversos pontos que poderiam ser melhorados para tornar efetivo 0 trabalho de Educação Ambiental na escola. Faz-se aqui o relato de algumas alternativas que podem auxiliar no processo de melhoramento do trabalho.

\section{1) O Planejamento das ações por meio do Projeto Político-Pedagógico - PPP}

De posse de um primeiro diagnóstico situacional, o passo seguinte é a elaboração de um Projeto Político Pedagógico (PPP) sobre Educação Ambiental. O Projeto Político Pedagógico é um documento identitário com a proposta educacional para o grupo em questão, apresentando desde seus referenciais conceituais, filosóficos e políticos, até a forma como o trabalho será operacionalizado. As ações podem ser direcionadas ao grupo em geral como também podem ser direcionadas a subgrupos específicos (BRASIL, 2008). Trata-se de um documento dinâmico que deve ser revisado temporariamente para se adequar a realidade, desenvolvimento e vivência do grupo.

É no PPP que devem estar descritas todas as intenções, valores, diagnósticos, justificativas, objetivos, metodologias e resultados esperados pelo grupo, bem como as estratégias de avaliação da eficácia das ações. Para a avaliação, o ideal é que se estabeleçam indicadores de desempenho - que, segundo a Fundación Chile (2009), são ferramentas de avaliação por meio das quais é possível descrever o estado ou valorar o êxito das ações - bem como a 
definição dos níveis mínimos de qualidade, que permitem que a escola meça com periodicidade definida e acompanhe no decorrer do tempo o nível de êxito das Linhas de Ação propostas, bem como o desvio das metas estabelecidas.

Outra questão importante é quanto à responsabilidade pela elaboração do plano. Segundo Silva (2009, pag. 88), "torna-se indispensável que o gestor escolar lidere a realização do Projeto Político-Pedagógico o qual deve estabelecer as propostas elaboradas pela comunidade intra e extraescolar". Porém, vale ressaltar que, uma vez pertencente e identitário ao grupo, é coerente que o PPP seja elaborado por meio da participação de todos os envolvidos. Sua avaliação e revisão periódica também devem ser participativas. A participação da comunidade externa, principalmente das famílias dos alunos, também poderá ser prevista em todas as fases do PPP, desde sua elaboração, passando pela execução e avaliação, até sua revisão. O ideal é que se incluam no PPP, além das estratégias de desenvolvimento dos alunos, estratégias voltadas à capacitação contínua dos professores.

A capacitação dos professores deve preceder a realização das atividades com os alunos, no intuito de nivelar os conhecimentos e organizar as práticas previstas no PPP. A capacitação dos professores pode envolver encontros temáticos, leitura de textos, rodas de discussão, dinâmicas, apresentação de trabalhos, vivências, teatralização, palestras ou mesmo trabalhos específicos para atender necessidades individuais como orientações e estudos autônomos. Um cuidado deve ser tomado quando na presença conjunta de professores ouvintes e surdos no trabalho, uma vez que se deve promover meios de que ambos participem e entendam as mensagens transmitidas.

Para este trabalho de capacitação o ideal é que a direção escolar conte com o apoio de um facilitador, ou um grupo de facilitadores, que tenha conhecimento amplo sobre Educação Ambiental e que possa preparar o grupo de docentes para que eles mesmos tenham autonomia em desenvolver as práticas previstas no PPP. O facilitador também poderá participar da execução do PPP, mas sempre como um apoio, lembrando que os principais responsáveis pela execução do plano são os próprios educadores.

\section{2) Os materiais em Língua Brasileira de Sinais (Libras)}

Uma das críticas feitas por professores durante a pesquisa descrita em Pereira (2013) foi quanto a indisponibilidade de materiais de Educação Ambiental, como cartilhas, filmes, panfletos e livros na língua legítima dos surdos, a Libras, uma vez que boa parte desses materiais está disponível somente em sua segunda língua, o português. A linguagem e a língua são prérequisitos para que ocorra o diálogo (BARBOSA, apud COIMBRA, 2004), para se referir e discursar sobre a realidade deve-se lançar mão de uma linguagem apropriada, utilizando-se mesmo do linguajar próprio do contexto onde se está inserido. 
Neste caso, se o trabalho ou material de Educação Ambiental não leva em consideração a língua própria do surdo, mesmo sendo o português sua segunda língua, sua eficácia poderá ser comprometida. Acredita-se que o trabalho com o surdo baseado na cultura, percepção e língua próprias do surdo pode levar a melhores resultados. Esta afirmação foi corroborada pela pesquisa descrita em Pereira (2013), uma vez que foi relatado pelos professores que a maioria dos materiais acessíveis ao surdo (em Libras) tratavam da temática dos resíduos e justamente essa foi a abordagem que mais obteve sucesso na escola, culminando na criação de hábitos de coleta seletiva.

Dois caminhos podem ser tomados no que se refere a falta de material adaptado ao surdo: fazer a tradução dos materiais disponibilizados em língua portuguesa ou produzir materiais específicos para o surdo. Um exemplo de tradução são os curtas-metragens de temas variados com legenda em Libras disponibilizados no site filmesquevoam.com.br (2013), que podem ser utilizados com o público infanto-juvenil.

Seja qual for o caminho escolhido, será necessário um trabalho interdisciplinar, pois trata-se de questões que ultrapassam as dimensões pedagógicas do processo ensino-aprendizado e que envolvem a participação de outras especialidades, como psicólogos, psicopedagogos, professores de todas as disciplinas, engenheiros, médicos, educadores físicos, terapeutas ocupacionais, fonoaudiólogos, diagramadores, especialistas em sistemas de informações, editores gráficos, economistas, advogados e outros mais.

Para isso, é necessária a formação de parcerias, pois nem sempre as Instituições de Ensino contarão com todas essas especialidades em seu quadro de funcionários. Reforça-se aqui o papel social que todas as profissões devem assumir no desempenho de suas funções específicas, uma vez que é discutível o exercício profissional que, além de benefícios individuais ou financeiros, não traga benefícios sociais, ou seja, não colaborem para a qualidade de vida da coletividade. É necessária a formação de redes de apoio às Instituições de Ensino para o desenvolvimento desse trabalho. Chama-se a atenção também para o papel que cabe ao poder público: o de suprir as necessidades educacionais específicas dos grupos sociais ou, ao menos, apoiar ações que nascem da iniciativa da escola e de seus colaboradores. A falta de uma visão de conjunto e de um paradigma unificador pode comprometer todo o trabalho e esforço empreendidos.

\section{3) A integração dos trabalhos realizados}

No caso da escola para surdos que foi visitada, é possível que os trabalhos de socialização, de apoio ao desenvolvimento da identidade e da autonomia pessoal, de cultura, de saúde, de discussão política e econômica, de desenvolvimento humano e de atuação profissional realizados não estejam sendo considerados como Educação Ambiental, ocorrendo em separado e desconectados do que se desenvolve como sendo Educação Ambiental. O ideal 
é que se faça a integração das ações, uma vez que todas elas visam ao mesmo objetivo: preparar o indivíduo para a vivência em sociedade.

Por meio dessa integração, pode-se alcançar a discussão do meio ambiente de forma ampla, abordando tanto o meio ambiente físico, quanto o construído, o do trabalho e o cultural, além de abordar a complexidade das interrelações entre homem, meio ambiente e qualidade de vida.

Para tanto, se faz necessária que a discussão do meio ambiente se faça por todas as profissões. Coimbra (2004) faz uma crítica com relação a esse fato. Para o autor, a questão ambiental não pode mais ser entendida apenas como parte das Ciências Biológicas. A discussão do meio ambiente clama por outros ramos do saber científico. Seria necessário passar da atual visão (calcada no pertencimento do tema meio ambiente às ciências naturais e biológicas) para uma visão sistêmica, que promove o tratamento interdisciplinar dos problemas vivenciados.

Pereira, Silva e Fernandes (2011, pag. 11) relatam em seu artigo que "o trabalho educacional tem melhores resultados quando desenvolvido por meio da interdisciplinaridade, devido à contribuição que cada área do conhecimento pode oferecer na obtenção dos resultados". Sendo assim, não existe disciplina ou professor que esteja desvinculado, ou que não se relacione ao meio ambiente; é o trabalho de todos que levará a resultados concretos.

\section{Conclusões}

Foram apresentadas algumas estratégias comumente utilizadas para Educação Ambiental de pessoas ouvintes e discutido o desafio da adequação dessas estratégias para o público surdo, uma vez que seu aprendizado ocorre de forma diferente dos ouvintes. A Educação Ambiental, apesar de ser essencial na educação básica, ainda carece de estratégias e instrumentos adequados que possam ser utilizados pelos professores para o trabalho com os alunos surdos, sendo necessário apoiar aos educadores na adaptação dessas estratégias e na construção de outras que se adequem à cultura surda.

A Educação Ambiental só cumprirá seu papel integrador quando se pensar em atingir aos diferentes na sua diferença, uma vez que a comunidade surda, historicamente à margem de muitos direitos, é também um agente de transformação social em plena capacidade de moderar mudanças em seu meio.

Espera-se que este trabalho possa motivar a pesquisa sobre materiais e estratégias aplicáveis à Educação Ambiental voltada aos surdos, visto que a abordagem baseada em materiais da língua portuguesa ou apenas baseada na discussão em sala é limitada, comprometendo, consequentemente, os seus resultados. 


\section{REFERÊNCIAS}

ALBUQUERQUE, J. Educação Ambiental para surdos. 2009. Disponível em: $<$ http://www.fimca.com.br/ver noticia.asp?id=1283>. Acesso em: 15 out. 2012.

BARBOSA, I. Estudos de textos acadêmicos. In: CUNHA, Valeska Guimarães Rezende da et al. Metodologia do Trabalho Científico. Uberaba: UNIUBE, [200-?].cap 2. p. 29-58.

BRASIL. Lei no 9.795 de 27 de abril de 1999. Dispõe sobre a Educação Ambiental, institui a Política Nacional de Educação Ambiental e dá outras providências. In: SARAIVA. Legislação de Direito Ambiental. São Paulo: Saraiva, 2008. 872 p. ISBN 978-85-02-06834-6. (Coleção Saraiva de Legislação).

BRASIL. Ministério do Meio Ambiente. Viveiros Educadores: plantando vida. Brasília, 2008. 84p. ISBN 978-85-7738-092-3.

COIMBRA, J.A.A. Linguagem e percepção ambiental. In: PHILLIPPI JR, A.; ROMÉRO, M.A.; BRUNA, G.C. (Ed.). Curso de Gestão Ambiental. Barueri: Manole, 2004. cap. 15. p. 525-570. ISBN 85-204-2055-9. (Coleção Ambiental; 1).

DEMAMANN, S.T. Educação Ambiental e representações sociais na educação de surdos. 2006. 109 f. Dissertação (Mestrado em Educação). Universidade Federal de Santa Maria, Santa Maria, 2006.

DIÁRIO DA MANHÃ. A Educação Ambiental no ensino de alunos surdos. 2011. Disponível em: <www.diariodamanha.com/noticias. asp?id=12317>. Acesso em: 15 ago. 2012.

FILMES que voam. C2011. Disponível em: $<$ http://www.filmesquevoam.com.br/canais.php?categoria=10>.Acesso em: 13 dez. 2013.

FUNDACION CHILE. Manual para o Diagnóstico Institucional e o desenho do Plano de Melhoramento. o que podemos fazer para melhorar? aplicação do ciclo de melhoramento contínuo da gestão escolar. [Caderno 1]. 2009. 32 p. Disponível em: $<$ http://www.gestaoescolardequalidade.org.br/manuales/Fichas de Apoio Apli cacao CMC.pdf >. Acesso em: 20 fev. 2012.

GOLDFELD, M. Breve Relato sobre a Educação dos Surdos. In: A Criança Surda: linguagem e cognição numa perspectiva sociointeracionista. 2. ed. São Paulo: Plexus, 2002. cap. 2. p. 24-43.

JUNQUEIRA, R.G.P. Pedagogia social: processos de intervenção socioambientais. In: JÚNIOR, L.A.F. (Org.). Encontros e Caminhos: formação de educadoras (es) ambientais e coletivos educadores. Brasília: Ministério do Meio Ambiente, 2007. v. 2, p. 245-252. ISBN 85-7738-044-0. 
MAZZINI, A.L.D.A. Dicionário Educativo de Termos Ambientais. 2. ed. Belo Horizonte, 2004. 384p. ISBN 85-903 655-1-4.

MENDONÇA, R. Educação Ambiental vivencial. In: JÚNIOR, L.A.F. (Org.). Encontros e Caminhos: formação de educadoras (es) ambientais e coletivos educadores. Brasília: Ministério do Meio Ambiente, 2007. v. 2, p. 118-129. ISBN 85-7738-044-0.

MELO, J.V. Educação Ambiental com crianças: como desenvolver?: curso, 7 de mai. 2011. Centro Educacional de Uberaba, Uberaba. 32 slides, color.

PEREIRA, C.A.R. A Educação Ambiental para Surdos na educação básica. Revista Eletrônica do Mestrado em Educação Ambiental, v. 30, n.2, p. 6 - 26, jul./dez. 2013

PEREIRA, C.A.R. et al. A percepção socioambiental no planejamento de ações educativas e de atenção primária. Fazu em Revista, Uberaba, n. 8, 2011. Disponível em: $<$ http://www.fazu.br/ojs/index.php/fazuemrevista/article/view/266>. Acesso em: 12 abr. 2013.

PEREIRA, C.A.R.; SILVA, I.A.V.; FERNANDES, A.L.T. Interdisciplinaridade no Acolhimento e Assistência Infantil: a atuação em projetos educacionais. In: Centro Universitário de Franca. (Org.). Anais do 5 Congresso de Iniciação Científica: Teorias \& Práticas em Pesquisas Multidisciplinares. Franca: Centro Universitário de Franca, 2011, v. 5, p. 203-215.

SILVA, E.P. A importância do gestor educacional na instituição escolar. Conteúdo. Capivari, v.1, n. 2, jul/dez. 2009. Disponível em: $<$ http://www.conteudo.org.br/index.php/conteudo/article/viewFile/21/23 >.

Acesso em: 27 fev. 2012.

STROBEL, K. As imagens do outro sobre a cultura surda. Florianópolis: UFSC, 2008. $118 \mathrm{p}$.

TRAJANO, F.M.; OLIVEIRA, D.F.; SOUSA, A.A.P. et al. Educação Ambiental: uma ação de cidadania na escola estadual de audio comunicação - EDAC. In: Congresso Brasileiro de Química, 48., 2008, Rio de Janeiro. Trabalhos ... Rio de Janeiro: FIRJAN, 2008.2 Disponível em: $<$ http://www.abq.org.br/cbq/2008/trabalhos/5/5-524-4567.htm>. Acesso em: 01 de fev. 2013. 